Revue

Revue de l'histoire des religions

de Ihistoire

des religions

$3 \mid 2017$

Varia

\title{
L'extraordinaire chrétien chez les Zouaves pontificaux : Joseph-Louis Guérin (1838-1860) mort en odeur de sainteté
}

The Christian Supernatural among the Papal Zouaves : the Case of Joseph-Louis Guérin (1838-1860), who Died in an Odor of Sanctity

Laurent Gruaz

\section{OpenEdition}

Journals

Édition électronique

URL : http://journals.openedition.org/rhr/8757

DOI : ERREUR PDO dans /localdata/www-bin/Core/Core/Db/Db.class.php L.34 : SQLSTATE[HYO00]

[2006] MySQL server has gone away

ISSN : 2105-2573

Éditeur

Armand Colin

Édition imprimée

Date de publication : 1 septembre 2017

Pagination : 485-517

ISBN : 978-2-200-93127-8

ISSN : 0035-1423

Référence électronique

Laurent Gruaz, «L'extraordinaire chrétien chez les Zouaves pontificaux : Joseph-Louis Guérin

(1838-1860) mort en odeur de sainteté », Revue de I'histoire des religions [En ligne], 3 | 2017, mis en

ligne le 01 septembre 2019, consulté le 08 janvier 2021. URL : http://journals.openedition.org/rhr/8757 ; DOI : https://doi.org/10.4000/rhr.8757 


\section{L'extraordinaire chrétien chez les Zouaves pontificaux : Joseph-Louis Guérin (1838-1860) mort en odeur de sainteté}

Entre 1860 et 1870, près de 11000 volontaires catholiques du monde entier ont défendu par les armes le pouvoir temporel du pape Pie IX, menacé par le roi de Sardaigne désireux de réaliser l'unité italienne. Prêts à se sacrifier, ils ont rejoint un corps spécialement créé pour eux: les Zouaves pontificaux. Joseph-Louis Guérin, séminariste breton de 22 ans, s'est engagé parmi les premiers. Il est mort quelques semaines plus tard en odeur de sainteté, après avoir livré sa première bataille. Très vite, les rumeurs de miracles dus à son intercession sont apparues. Un dossier a même été constitué en vue d'une éventuelle instruction canonique mais n'a jamais dépassé ce stade malgré une quarantaine de témoignages de "guérisons miraculeuses » et un culte populaire qui s'est développé pendant plus d'un siècle.

\section{The Christian Supernatural among the Papal Zouaves : the Case of Joseph-Louis Guérin (1838-1860), who Died in an Odor of Sanctity}

Between 1860 and 1870, about 11000 Catholic volunteers from all around world took up arms to defend the temporal power of Pope Pius IX against the king of Sardinia, who wanted to unify Italy. Ready to sacrifice themselves, they enlisted in a new corps especially created for them: the Papal Zouaves. Joseph-Louis Guérin, a 22-year-old Breton seminarian, was one of the first to volunteer. He died a saintly death only a few weeks later, after the first battle. Soon after, rumors of miracles due to his intercession began. A file was constituted in order to canonize him but was unsuccessful, despite about 40 testimonies of miraculous recoveries and a popular cult devoted to him that lasted more than a century. 
Les croisés ont eu leurs saints en leur temps, il peut donc sembler juste que les soldats de la «neuvième croisade ${ }^{1}$, quelque neuf siècles plus tard, aient les leurs. Entre 1860 et 1870, près de 11000 volontaires catholiques du monde entier ont rejoint Rome pour défendre le pouvoir temporel du pape Pie IX, menacé par le roi de Piémont-Sardaigne désireux de réaliser l'unité italienne. Parmi eux, environ 3000 étaient Français dont la majorité des officiers du Régiment des Zouaves Pontificaux. Il aurait paru étonnant qu'à Rome, près du pape Pie IX, béatifié en 2000, pour une cause aussi «sainte» que celle de la défense des États pontificaux, à une période où les apparitions mariales étaient fréquentes en France, et alors que de nombreux engagés rêvaient du martyre ${ }^{2}$, il n'y ait pas eu quelques velléités d'instruction de procès en canonisation de Zouaves français. En réalité, il n'y en a eu qu'un seul, celui de Joseph-Louis Guérin. Plusieurs témoignages de miracles opérés sur des zouaves ou des membres de leurs familles, notamment des officiers, ont été recensés, mais c'est uniquement le dossier du jeune volontaire breton, blessé lors de la première bataille livrée par les soldats du pape à Castelfidardo et mort en odeur de sainteté à l'âge de 22 ans, qui a été constitué en vue d'une éventuelle instruction canonique. Il n'a cependant pas franchi ce stade malgré des dizaines de guérisons inexpliquées, près d'une quarantaine de témoignages miraculeux et un culte populaire qui s'est développé pendant plus d'un siècle, jusque dans les années 1950, en France.

\section{RENOUVEAU DE LA RECHERCHE SUR LES ZOUAVES PONTIFICAUX}

Les sources concernant les Zouaves pontificaux sont nombreuses et relativement accessibles ; celles sur Joseph-Louis Guérin sont plus rares et essentiellement constituées de témoignages et

1. Jules Delmas, La Neuvième Croisade, Paris, Blériot, 1861, 428 p.

2. Bruno Horaist, La dévotion au pape et les catholiques français sous le pontificat de Pie IX (1846-1878), d'après les archives de la Bibliothèque apostolique vaticane, Rome, École française de Rome (Collection de l'École française de Rome, n 212), 1996, p. 58. 
correspondances émanant de compagnons d'armes ou de séminaire qui se sont exprimés spontanément sur le sujet mais aussi à la demande du Supérieur du séminaire de Nantes, probablement dans le cadre d'une enquête diocésaine de réputation de sainteté. Ils sont pour l'essentiel conservés aux Archives départementales de Loire-Atlantique. Ce fonds, répertorié 125J-7G 2, comprend aussi des signalements de faits miraculeux de provenances diverses. Le dossier a été reclassé en 1926 et la masse de documents qu'il comporte est de première main. On y trouve également des reliques: une image peinte du petit Zouave sur planchette $(18 \times 23 \mathrm{~cm})$, non datée, et deux petits tubes de verre scellés contenant l'un des cheveux, l'autre une moitié de son scapulaire, ainsi que la biographie de l'abbé Allard sur Le Volontaire JosephLouis Guérin, du corps des Zouaves Pontificaux. La première édition de cette biographie date de 1860, l'ouvrage a rapidement été épuisé et deux autres éditions ont vu le jour en 1861 et 1862. Principalement composée des lettres de Guérin, la première mouture ${ }^{3}$ se contentait de délivrer sur une petite centaine de pages les commentaires enflammés de l'auteur. Plus complète, la dernière édition déroule au contraire l'histoire de la vie du jeune séminariste et soldat sur plus de 300 pages $^{4}$. Le ton est toujours enthousiaste mais l'ouvrage est mieux structuré autour de douze chapitres qui offrent de précieuses informations et anecdotes. L'auteur ne fait, toutefois, qu'évoquer les «faits miraculeux obtenus par l'intercession du jeune martyr, [les] guérisons nombreuses survenues à la suite de prières faites en son honneur [et les] pèlerinages accomplis à son tombeau $»^{5}$, sans commenter dans le détail ces manifestations. Les Archives du grand séminaire de Nantes conservent, de leur côté, la relation brève mais détaillée de trois guérisons inconnues ou tout au moins jamais exploitées, survenues, l'une en 1865 , l'autre en 1866 et la dernière en $1873^{6}$; quant aux Archives diocésaines de Poitiers, elles renferment un

3. Julien S. Allard (abbé), Le Volontaire Joseph-Louis Guérin, du corps des Zouaves Pontificaux, né à Sainte-Pazanne le 5 avril 1838, mort à Osimo le 30 octobre 1860, Nantes, imp. Félix Mazeau, 1860, 98 p.

4. Julien S. Allard (abbé), Le Volontaire Joseph-Louis Guérin, du corps des Zouaves Pontificaux, né à Sainte-Pazanne le 5 avril 1838, mort à Osimo le 30 octobre 1860, Nantes, Bourgeois, 1862, $311 \mathrm{p}$.

5. Ibid., p. 304.

6. Archives diocésaines de Nantes, 2H/087 
document relatif à la guérison de Marie-Anne Moriceau, attribuée en 1861 au jeune Zouave ${ }^{7}$. Si le cas de Guérin est cité dans plusieurs ouvrages hagiographiques sur les Zouaves en général, un article de Marius Faugeras porte directement sur les miracles attribués à Joseph Guérin ${ }^{8}$. Cette publication offre des analyses statistiques croisées et des tentatives de classement originales, que ce soit sur l'origine des "miraculés », leur milieu familial et socioprofessionnel, les maladies guéries ou présumées telles, ou encore la réaction du clergé et l'attitude du corps médical. Malgré cet apport conséquent d'informations, l'auteur ne développe pas véritablement la «canonisation populaire » et la ferveur dont le jeune thaumaturge a fait l'objet pendant près d'un siècle, à travers notamment les nombreuses processions et appositions d'ex-voto auxquels il ne consacre que deux courts paragraphes. Si l'auteur se défend de prendre parti, il n'hésite pas à reconnaître le caractère « troublant» de certaines guérisons.

Pour mieux cerner l'intérêt que représente l'étude de la vie de Joseph-Louis Guérin, des conditions de sa mort et de sa réputation de sainteté qui s'ensuivit, il convient de la replacer dans l'histoire de l'Église de France du Second Empire et le contexte plus large de l'unité italienne, principale préoccupation de la Maison de Savoie qui, en voulant faire de Rome la capitale de son futur royaume unifié, allait mettre fin au pouvoir temporel du pape et à l'État pontifical qui représentait alors près du tiers de la péninsule.

Né à Sainte-Pazanne (Loire-Inférieure) en 1838, Guérin est, par ses origines, sa formation et son engagement, fort représentatif du renouveau catholique de la première moitié du XIX ${ }^{\mathrm{e}}$ siècle. Troisième d'une fratrie qui compte deux aînés morts en basâge, né au sein d'une famille au statut social modeste - son père est cordonnier à Sainte-Pazanne puis à L'Épine, en l'île de Noirmoutier - il grandit dans une foi profonde et des principes religieux stricts, et dès 1851 , il se destine à la prêtrise, étudiant d'abord au petit séminaire de Guérande puis à celui de Nantes, enfin, en 1859, au grand séminaire de la même ville, sa petite taille $(1,56 \mathrm{~m})$ l'ayant fait réformer lors du conseil de révision.

7. G 8, Guérisons miraculeuses, boîte 1 .

8. Marius Faugeras, "Le Zouave pontifical Joseph Guérin et ses miracles », dans Histoire des miracles. Actes de la $6^{e}$ Rencontre d'histoire religieuse tenue à Fontevraud les 8 et 9 octobre, Angers, Presses de l'Université, 1983, p. 131-141. 
Lorsqu'il décide de répondre à l'appel du général de La Moricière qui réorganise si ce n'est improvise à la hâte une armée pontificale, les exploits des premiers Zouaves tombés pour le pape n'existent pas encore : ce sont bien sa mort et celle de ses compagnons tués au combat, ainsi que leur courage au feu tant loué par leurs chefs qui vont inspirer un élan d'enthousiasme envers la petite armée pontificale qui voit alors ses effectifs progresser rapidement. Les ouvrages qui suivent la «glorieuse défaite de Castelfidardo $»^{9}$ ne manquent d'ailleurs pas de faire l'éloge de ces milites Christi et leurs titres évocateurs connaissent un large succès auprès d'une frange de catholiques français; ils font le bonheur de la jeunesse qui fréquente les nombreux établissements congréganistes, notamment ceux de la Compagnie de Jésus au sein desquels sont naturellement encouragées les vocations pour rejoindre Rome ${ }^{10}$ et suivre les traces de leurs aînés.

L'un des tout premiers ouvrages parus sur les Zouaves pontificaux a été écrit par Jules Delmas, que l'on peut considérer comme le premier historien du bataillon. Son livre La neuvième croisade, a été publié dès 1861. Le titre est révélateur de la perspective historique et mystique sur l'action des Zouaves; les patriotes italiens, les garibaldiens, les républicains, les francsmaçons et les juifs censés les soutenir sont assimilés à l'Antéchrist. Sans doute a-t-il «donné le ton» aux auteurs qui ont suivi et les a-t-il influencés dans une certaine mesure. La même année, sortent en librairie La croisade d'Italie en $1860^{11}$ et Les martyrs de Castelfidardo $^{12}$. Le choix des mots «croisade» et «martyrs» n'est pas innocent car pour leurs nombreux zélateurs, les Zouaves pontificaux ne défendent pas seulement un État mais la vraie foi.

Plus proche de nous, La dernière guerre du Pape de Jean Guénel ${ }^{13}$ s'appuie sur de nombreuses archives inédites

9. L'Avant-Garde $\mathrm{n}^{\circ} 211,1^{\mathrm{er}}$ octobre 1899.

10. Notamment le collège Saint-François-Xavier, de Vannes. Voir Anonyme, Inauguration d'un monument élevé à la mémoire des anciens élèves morts devant l'ennemi, Vannes, Galles, 1878.

11. Vicomte de La Vausserie, La croisade d'Italie en 1860. Histoire de l'Armée Pontificale, Paris, Librairie A. Josse, 1860, 287 p.

12. Anatole de Ségur, Les Martyrs de Castelfidardo, Paris, Ambroise-Bray, 1861.

13. Jean Guénel, La dernière guerre du Pape. Les Zouaves pontificaux au secours du Saint-Siège 1860-1870, Rennes, Presses universitaires de Rennes, 1998, 196 p. 
des familles de La Poëze et Le Gonidec de Traissan ${ }^{14}$, et offre un recul intéressant sur cette période de l'histoire jusque-là traitée, pour l'essentiel, de façon partiale. L'auteur, professeur de médecine et descendant de Zouave pontifical, ne fait cependant qu'évoquer Guérin en quelques lignes, reprenant d'ailleurs Marcel Launay qui lui accordait quelques pages disséminées dans son grand ouvrage sur le diocèse de Nantes ${ }^{15}$. Le propos de ces deux auteurs est intéressant dans la mesure où il précise que les faits miraculeux que l'on attribuait à Guérin excitaient les vocations des jeunes prêtres ou séminaristes: «Une véritable épidémie de départs se répandait dans le diocèse $»^{16}$. La thèse de Patrick Nouaille-Degorce sur Les Volontaires de l'Ouest ${ }^{17}$, qui porte sur le prolongement du Régiment des Zouaves comme corpsfranc au sein de l'armée française s'illustrant pendant la guerre de 1870, insiste sur la prégnance du modèle christique et la thématique de l'expiation. On peut citer aussi l'ouvrage collectif de Bruno Dumons et Jean-Philippe Warren ${ }^{18}$, qui vaut surtout par la mise en perspective des motivations des engagés de trois pays francophones. Mais l'étude la plus complète à ce jour reste celle réalisée par Alain Pichon ${ }^{19}$, qui traite non seulement de ce régiment en particulier mais aussi des Volontaires de l'Ouest et de la Légion d'Antibes.

\section{Trois AUTRES CAS SIMILAIRES AU BATAILlON}

Les Zouaves pontificaux français sont nombreux à offrir un profil similaire à celui de Guérin, et la dimension sacrificielle de

14. Archives départementales de Loire-Atlantique, $200 \mathrm{~J}$.

15. Marcel Launay, Le diocèse de Nantes sous le Second Empire, Tome II, Nantes, Cid Éditions, 1982, 979 p.

16. Ibid., p. 737. Voir aussi Guénel, op. cit., p. 46.

17. Patrick Nouaille-Degorce, Les Volontaires de l'Ouest: histoire et souvenir, de la guerre de 1870-1871 à nos jours, thèse de doctorat, Université de Nantes, 2005.

18. Bruno Dumons, Jean-Philippe Warren (dir.), Les Zouaves pontificaux en France, en Belgique et au Québec. La mise en récit d'une expérience historique transnationale (XIX'-XX ${ }^{e}$ siècles), Bruxelles, Bern, Berlin, Peter Lang, 2015. $157 \mathrm{p}$.

19. Alain Pichon, «Les Zouaves Pontificaux», Toulouse, Le Colback, bulletin $\mathrm{n}^{\circ} 12$, s. d. 
leur engagement se retrouve tout au long des dix années d'existence du corps. Trois autres zouaves méritent particulièrement d'être mentionnés : le jeune voyant de la Salette Maximin Giraud, engagé pour six mois en 1865, le sergent Joseph Rialan ${ }^{20}$ et le sergent Paul-Marie Saucet ${ }^{21}$. Le premier apparaît, lors de son engagement, non seulement comme le témoin privilégié d'une manifestation divine mais aussi, et de fait, comme le symbole d'une réponse tout aussi divine aux tentatives de spoliation bien réelles des États pontificaux $^{22}$. Le second meurt à la bataille de Mentana en 1867, la deuxième grande bataille livrée par les Zouaves, sept ans après Castelfidardo, et est très vite appelé « le Guérin de $1867 »^{23}$ : «Il était l'édification de sa compagnie. Tous ses frères d'armes disent que le bon Dieu s'est choisi en lui la plus sainte victime $»^{24}$ et l'abbé Daniel, aumônier des Zouaves, affirme que «le bon Dieu nous fait la grâce d'avoir un nouveau Guérin aux Zouaves $»^{25}$. Quant au troisième, s'il ne fait pas l'objet d'une vénération particulière, sa réputation de sainteté au sein du bataillon et sa vie exemplaire ont été reconnues de façon concrète par des hauts gradés du régiment et le général de Charette, alors commandant en second du corps des Zouaves, a fait inhumer, en 1865, son épouse dans le cimetière Saint-Laurent, de Rome, à côté de la tombe de Paul-Marie Saucet.

Lors de la bataille de Castelfidardo, Saucet avait, en effet, sauvé la vie du capitaine de Charette en le plaquant au sol alors qu'un tireur piémontais venait d'abattre le soldat qui les précédait et s'apprêtait à mettre Charette en joue ${ }^{26}$. L'exemplarité du geste de cet humble fils de concierge de la mairie de Nantes, pas du tout

20. Robert Oheix, Joseph Rialan, sergent aux Zouaves pontificaux, Paris, Lecoffre, 1868, $377 \mathrm{p}$.

21. Jacques Saucet, «Un jeune bazougeais, archétype des Zouaves pontificaux : Paul Saucet (1842-161)», dans Bulletin de la Société archéologique et historique de l'arrondissement de Fougères, Tome XXX, 1992, 16 p.

22. Laurent Gruaz, «Maximin Giraud, le berger de La Salette : de l'Apparition de la Vierge aux soldats du Pape », dans Chrétiens et sociétés, n 17, 2011, p. 170.

23. Robert Oheix, op. cit., p. 337.

24. Lettre de l'abbé Peigné, aumônier des Zouaves à l'Évêque de Nantes, Rome, 8 novembre 1867, citée dans Robert Oheix, op. cit., p. 296.

25. Abbé Daniel, cité dans Robert Oheix, op. cit., p. 343-344.

26. Henri Le Chauff de Kerguenec, Souvenirs des Zouaves pontificaux 1861 et 1862. Recueillis par François Le Chauff de Kerguenec. Ancien Zouave Pontifical, Tome I, Poitiers, Oudin, 1890, p. 201 et suiv. 
rompu au combat, mais qui a risqué sa vie pour sauver celle de son capitaine, a aussitôt été entièrement associée à l'ensemble des volontaires du pape. Il s'est rapidement développé et renforcé à travers les aumôniers et les officiers qui ont ainsi largement loué ce comportement héroïque et désintéressé, et l'ont insufflé à leurs hommes. Cette conduite courageuse et altruiste n'était cependant pas nouvelle pour eux, qui avaient été éduqués et instruits en majorité chez les Jésuites, et elle correspondait bien à la piété sacrificielle et au dolorisme de l'époque ${ }^{27}$. L'exemple de JosephLouis Guérin reste cependant le seul à faire autant l'unanimité.

On peut penser qu'en cette période particulière de l'histoire du XIX ${ }^{e}$ siècle, au moment où les États millénaires du Souverain Pontife jouent leur survie face à l'invasion piémontaise au nord et garibaldienne au sud, découvrir un saint dans ce nouveau corps de volontaires, alors en création, aurait pu avoir quelque conséquence politique bienvenue afin de le justifier, tout en remettant en cause la légitimité de l'attaque des Piémontais aux yeux des puissances catholiques européennes. Mais la vie «pieuse et sainte » de Guérin préexiste à toute initiative de la sorte, et les témoignages en ce sens sont nombreux et variés, aussi cela mérite-t-il que nous nous arrêtions, en premier lieu, sur la vie du jeune séminariste et soldat afin d'essayer de mieux comprendre qui il était et comment il était perçu. Les signalements miraculeux et témoignages de faits « extraordinaires », ainsi que le développement d'un culte populaire autour de sa personne permettront, dans un second temps, d'apprécier l'importance de ces manifestations, avant d'essayer d'analyser les raisons pour lesquelles, malgré toutes ces manifestations, son procès en béatification n'a jamais été ouvert.

\section{MOURIR EN MARTYR}

En août 1860, Joseph-Louis Guérin répond à l'appel du pape, qui souhaite former une armée de volontaires catholiques pour défendre ses États, et fait partie des tout premiers à rejoindre l'éphémère corps créé un mois plus tôt par Henri de Cathelineau,

27. Philippe Boutry, Prêtres et paroisses au pays du curé d'Ars, Paris, Les Éditions du Cerf, 1986, 706 p. ; Dominique Avon, Philippe Rocher, Les jésuites et la société française (XIX et XX siècles), Toulouse, Éditions Privat, 2001,288 p. 
petit-fils du chef royaliste des Vendéens Jacques Cathelineau, surnommé le Saint de l'Anjou. Baptisé par ses soins les Chevaliers de Saint-Pierre, ce corps est aussi connu sous le nom de Croisés de Cathelineau, et ceux qui s'y engageaient se réclamaient de cette double appellation. Il était formé d'une soixantaine de volontaires portant, notamment, « un gilet marron avec, au cœur, une croix blanche $»^{28}$. Cette croix blanche sur le torse et le nom du corps ont fait de nombreux envieux chez les Tirailleurs Franco-Belges. Le général de La Moricière, commandant en chef de l'armée pontificale en 1860, ne voulant pas de régime d'exception, a exigé leur incorporation dans le Bataillon Franco-Belge. Finalement, les Croisés ont accepté de rejoindre le rang, formant ainsi la $4^{\mathrm{e}}$ compagnie, mais la légende était née, et les Zouaves, en particulier leurs officiers, s'en sont réclamés. Guérin, mort en octobre 1860, n'a jamais fait partie du Régiment des Zouaves pontificaux qui s'est officiellement formé le $1^{\text {er }}$ janvier 1861 sur les « glorieux débris $»^{29}$ du Bataillon des Tirailleurs Franco-Belges.

L'engagement de Guérin, s'il bénéficie de l'appui familial, se fait évidemment au mépris de la politique étrangère impériale, en bravant les menaces de rétorsion administrative, et sans l'assentiment de la hiérarchie ecclésiastique, le supérieur du séminaire, l'abbé Féret, et l'évêque, Monseigneur Jaquemet, qui redoutent un soudain tarissement de leur clergé. Si l'appel du pape et la guerre contre les Piémontais sont pris très au sérieux, Guérin considère toutefois son enrôlement comme une sorte de divertissement : «Cette ardeur qu'il avait pour les jeux, il la retrouva pour les combats ; on eût dit que pour lui entre les uns et les autres, il n'y avait pas de différence, et qu'à ses yeux le plaisir était égal dans les deux cas $»^{30}$. Son séjour dans l'armée pontificale est vu comme un temps de liberté lequel, une fois terminé, lui permettra de s'engager ensuite dans les ordres : « Il passera ses vacances au milieu des combats, puis il reviendra $»^{31}$. Le jeune séminariste semble cependant conscient du danger qu'il encourt. Il se dit prêt

28. René Bittard des Portes, Histoire des Zouaves Pontificaux, Paris, Bloud et Gay, 1897, p. 12.

29. Henri Le Chauff de Kerguenec, Souvenirs..., op. cit., p. 101 et 186.

30. Julien S. Allard (abbé), Le Volontaire Joseph-Louis Guérin..., op. cit., p. 197-198.

31. Lettre de Joseph-Louis Guérin, juillet 1860, dans Ibid., p. 12. 
à aller jusqu'au bout et à donner sa vie s'il le faut : « Je demeure intimement convaincu qu'il me faut partir et mourir au besoin pour la sainte cause $»^{32}$, écrit-il à son curé au mois de juillet 1860, avant de lui confier à nouveau le mois suivant : «Je suis prêt à tous les sacrifices $»^{33}$. Il est loin d'être le seul dans ce cas ; «J'ai la prétention de faire un bon soldat romain et savoir mourir, s'il le faut, pour une sainte cause $»^{34}$, écrit le jeune Georges Myonnet ${ }^{35}$ alors qu'il n'a pas encore dix-huit ans. De son côté, dans l'attente de partir, Théodore Wibaux rédige des petits billets dans lesquels il note ses résolutions à tenir : «Courage Théodore, et persévère ! En acceptant l'épreuve et le sacrifice, tu as pris la meilleure part. Si tu es un jour un Zouave pontifical zélé, patient et chaste, quelle belle place t'attend au ciel ! $»^{36}$.

Le voyage de la Bretagne jusqu'à Rome, en ce début de seconde moitié du XIX ${ }^{\mathrm{e}}$ siècle, n'est pas de tout repos, et c'est tout le trajet de ce chemin de sainteté que ces jeunes gens acceptent d'emprunter jusqu'au sacrifice suprême qui peut être comparé à un ultime pèlerinage. C'est ce que le Zouave Oscar de Poli appelle «le grand voyage dont l'étape suprême est le Paradis! ${ }^{37}$. En chemin, ils ont prévu des arrêts, parfois de plusieurs jours, afin de satisfaire à leurs pieuses obligations. Joseph-Louis Guérin, quant à lui, effectue une première halte à Paris. Avec son compagnon Jean-Baptiste Pinsonneau, ils rencontrent le Père Savigne, un de leurs anciens directeurs de retraite au petit séminaire, et passent la journée « à visiter plusieurs églises de Paris, entre autres l'église de Notre-Dame des Victoires et [à prier] ensemble le Dieu des armées de vouloir bien répandre ses bénédictions sur [leurs] faibles bras que nous consacrerions à la défense de son Vicaire sur la terre $»^{38}$.

32. Lettre de Joseph-Louis Guérin, Noirmoutier, 22 juillet 1860, dans Ibid., p. 15.

33. Lettre de Joseph-Louis Guérin, août 1860, dans Ibid., p. 25-26.

34. Henri Le Chauff de Kerguenec, Souvenirs..., op. cit., tome I, p. 86.

35. Georges Myonnet, engagé à 18 ans dans le Bataillon des Franco-Belges, tué à Castelfidardo.

36. Charles du Coëtlosquet (s.j.), Théodore Wibaux, Zouave Pontifical et Jésuite, Paris, Retaux-Bray, 1886, p. 28.

37. Oscar de Poli, Souvenirs du bataillon des Zouaves Pontificaux, Paris, Dupray de La Mahérie, 1861, p. 107.

38. Lettre de Jean-Baptiste Pinsonneau au Supérieur du séminaire de Nantes, Archives diocésaines de Nantes, s.d. 
Guérin est serein. Égal à lui-même en toutes circonstances. Son ami raconte :

«Lorsque [le train] se mit en marche, c'est là surtout que je sentis ce que c'était que partir peut-être pour toujours sans avoir pu dire un dernier adieu à sa mère, et je me mis à pleurer comme un enfant. Mais mon cher compagnon de voyage qui était toujours calme se mit à me consoler et relever mon courage. "Nous partons", me dit-il, "les wagons nous emportent, récitons un Te Deum pour la grâce que Dieu nous a faite d'aller mourir pour sa cause, et un Veni Creator pour implorer les lumières du Saint-Esprit afin qu'il nous conduise heureusement à notre destinée" $»^{39}$.

À l'arrivée à Rome, après deux nuits en mer et encore une heure de train depuis Civitavecchia, la vue de la majestueuse coupole de Saint-Pierre dans le lointain semble vite faire oublier les moments difficiles : «Quelle ne fut pas notre émotion! [Guérin] était tellement ému qu'il avait peine à me parler. Dès le soir, nous allâmes visiter [...] le Vatican et la chambre qu'habitait le Souverain Pontife. Là encore, [il] fut pris d'une de ces émotions qui font du bien à l'âme $»^{40}$.

Guérin et son ami Pinsonneau commencent très vite leurs classes au sein du corps de Cathelineau.

« Dès le lendemain, nous quittâmes la soutane et Guérin put prendre rang parmi les Croisés. On nous fit faire d'abord l'école du soldat ce qui est pour les commençants, il y a aussi l'école du bataillon qui est pour ceux qui savent faire l'exercice. Guérin y mit tellement d'ardeur qu'au bout de 8 jours il entrait à l'école du bataillon, laissant derrière plusieurs qui étaient depuis plus d'un mois à l'école du soldat. [II] gagna l'affection de ses chefs et de tous ses compagnons d'armes qui l'aimaient et le respectaient surtout beaucoup $»^{41}$.

Après le licenciement des Croisés, Joseph-Louis Guérin rejoint les Franco-Belges et se voit attribuer le matricule $n^{\circ} 356$; il est affecté à la $4^{\mathrm{e}}$ compagnie, commandée par le capitaine adjudantmajor Louis de Chillaz. D'emblée les recrues quittent Rome pour le camp de Terni, à plus d'une centaine de kilomètres au nord. Les journées sont longues, plus de trente kilomètres à chaque étape par des chaleurs étouffantes et l'équipement dépasse les $30 \mathrm{~kg}$ : «Pour la première fois je mettais mon sac à dos tout au complet, il m'a

39. Ibid.

40. Ibid.

41. Ibid. 
paru un peu lourd les trois ou quatre premiers milles, mais après je m'y suis fait. [...] Sans avoir rien mangé, il a fallu avaler une côte raide de huit à neuf milles par une chaleur affreuse $»^{42}$, raconte Maximin Giraud. Le soir, il faut encore aller chercher de l'eau pour la compagnie. Les préposés à cette mission éprouvante sont généralement tirés au sort ; Guérin se porte pourtant régulièrement volontaire. Pinsonneau confirme qu'il le vit plusieurs fois aller en chercher sous une chaleur écrasante, "non seulement avec son bidon, mais avec tous ceux de son escouade et quelquefois les nôtres $»^{43}$. Et Padioleau ajoute que «souvent même, il n'était pas besoin d'un ordre. Demandait-on un homme de bonne volonté pour une corvée, on le voyait toujours le premier, oubliant ses aises et son repos et sortant de la tente s'il était couché $»^{44}$. De l'avis de ses camarades, Guérin endurait toutes les contrariétés du quotidien sans jamais se plaindre. Confiant, il s'en remettait entièrement à Dieu et se voulait bienveillant avec chacun :

«Cette manière d'agir rendait M. Guérin cher à tout le monde et lui donnait une influence sensible que plusieurs n'ont pu s'expliquer. Déjà consacré au Seigneur, il remplissait la mission que la providence lui avait secrètement inspirée. Il était là pour le salut de plusieurs et chaque fois que l'occasion se présentait d'exercer son zèle pour le salut des âmes il la saisissait avec empressement. [...] Son exemple animait les uns et ses paroles encourageaient, consolaient les autres $»^{45}$.

Le 18 septembre 1860, à Castelfidardo, l'armée piémontaise bouscule les maigres troupes pontificales dix fois inférieures ; le Bataillon Franco-Belge, seul, résiste vigoureusement mais est anéanti. Pour se représenter ce qu'a été ce premier véritable affrontement entre l'armée piémontaise et les soldats pontificaux, il faut imaginer une troupe de quelques milliers d'hommes mal équipés, sans véritable entraînement, qui s'élancent avec détermination face à une armée largement supérieure en nombre et en matériel, pour prendre d'assaut une crête avec, comme position intermédiaire à tenir, une ferme. Une bataille des plus sommaires mais dont l'enjeu - les deux tiers du territoire pontifical - est de taille.

42. Lettre de Maximin Giraud à Henri Le Chauff de Kerguénec, 8 septembre 1865, dans Souvenirs..., op. cit., p. 252-253.

43. Lettre de Jean-Baptiste Pinsonneau, op. cit.

44. Lettre d'Auguste Padioleau au Supérieur du séminaire, Nantes, 23 novembre 1860 .

45. Ibid. 
Pour ce premier assaut, le demi-bataillon des Tirailleurs FrancoBelges est encore moins bien loti que les autres corps pontificaux : sur les deux cent cinquante hommes qui le composent, les plus anciens comptent à peine trois mois de service. Quant aux nouveaux, leurs engagements ont été contractés parfois jusqu'au $1^{\text {er }}$ septembre 1860. Moins d'une centaine d'hommes, dont vingtcinq officiers, possédaient une formation militaire préalable. Au vu de cette impréparation manifeste et de ce manque d'hommes et de moyens, il semble légitime de se demander pourquoi, dans ces conditions, les Franco-Belges s'en vont à la rencontre d'une mort certaine sans même pouvoir espérer inverser le cours des événements? Sans doute parce que la dimension de ce premier combat est ailleurs. Elle est religieuse avant tout et peu importe le rapport des forces en présence. Ces jeunes volontaires se sont engagés dans le but de s'offrir pour sauver les États pontificaux, tant physiquement que spirituellement, et ainsi espèrent-ils racheter les péchés de la France qui aurait dû, selon eux, prêter mainforte au pape.

Au matin du 18 septembre, vers huit heures trente, le général de La Moricière et ses hommes quittent la petite bourgade de Lorette en direction d'Ancône. Dans le même temps, la colonne Pimodan se rassemble pour la première attaque du jour. Les troupes pontificales sont faibles : elles sont arrivées à la tombée de la nuit précédente, les hommes sont à jeun et accusent une semaine de marches difficiles à grandes étapes, à travers les montagnes ${ }^{46}$. Si certains régiments ne sont pas motivés pour combattre, ce n'est pas le cas des Franco-Belges, très excités par la perspective de leur premier engagement au feu. Guérin aussi est exalté : «Passant devant Lorette, il ne pouvait détacher ses regards de ce dôme qui recouvre la Santa Casa! Que de fois sur le champ de bataille, il aura imploré la protection de cette auguste reine des cieux. Il allait combattre sous ses yeux et contre les ennemis de son fils et de son sanctuaire. Aussi sa joie était-elle surprenante, admirable, indicible $»^{47}$.

Le symbole de Lorette est ici particulièrement important. La dimension de la bataille à venir se précise, elle est mariale. C'est ici, en effet, que, selon la tradition, a été transportée «l'heureuse

46. L'Avant-Garde $\mathrm{n}^{\circ} 439,1^{\text {er }}$ mars 1909, p. 29.

47. Lettre d'Auguste Padioleau, op. cit. 
maison de Nazareth » dans laquelle, après la salutation de l'ange adressée à Marie, le Verbe s'est fait chair. La Sainte Maison de Lorette a été le premier sanctuaire de portée internationale dédié à la Vierge et, pendant plusieurs siècles, le vrai cœur marial de la chrétienté $^{48}$. La présence de Lorette résonne à leurs yeux comme un double signe divin puisque, non seulement, les zouaves connaissent l'histoire de ce lieu où ils doivent se battre et peut-être mourir, mais c'est aussi là que Pie IX avait fait le vœu, à l'âge de 20 ans, de se consacrer au service de Dieu si la Vierge le guérissait de son épilepsie, et avait été exaucét9.

On ne connaît pas d'emblée les circonstances exactes de la blessure mortelle de Guérin, « au milieu de la fumée de la poudre et du sifflement des balles, à peine pouvait-on distinguer ses plus proches voisins $»^{50}$, ce qui ajoute au mystère. Victor Gros de Perrodil, ancien lieutenant de l'armée française, caporal dans la $4^{\text {e }}$ compagnie, celle de Guérin, l'a découvert au milieu du champ de bataille : «Il était là, couché sur le dos, et il regardait le ciel ; je m'inclinai pour le toucher, il était froid, glacé ; je me mis à genoux pour déposer sur ce front si pur un baiser [...] je pris sa cravate d'ordonnance, je lui fis mes adieux, je le croyais mort. [...] Il était tombé à quelques pas du bois où se trouvait l'ennemi $»^{51}$. Oscar de Poli, autre volontaire de la $4^{\mathrm{e}}$, précise que Guérin a été blessé un peu après la seconde charge à la baïonnette : «J'étais étendu avec un coup de baïonnette dans la poitrine et un autre au bras, mon sang coulait, ma poitrine était découverte, Guérin passa : "Adieu de Poli, me dit-il, adieu ! N'oubliez pas de dire : Jésus, Marie; adieu !" Cinquante pas plus loin, je le vis tomber $»^{52}$.

Joseph-Louis Guérin, grièvement blessé d'une balle à la poitrine qui lui a perforé un poumon, a d'abord été transporté au couvent des Minimes conventuels de Castelfidardo transformé, pour l'occasion, en infirmerie, puis à l'hôpital d'Osimo par les ambulances

48. Yves-Marie Bercé, Lorette aux XVI et XVII siècles. Histoire du plus grand pèlerinage des Temps modernes, Presses de l'université Paris-Sorbonne, 2011, $371 \mathrm{p}$.

49. Henri Bretonneau, Notice biographique sur notre Saint Père, le pape Pie IX, Gand, Vanryckegem-Lepère, 1847, p. 10.

50. Julien S. Allard (abbé), Le Volontaire Joseph-Louis Guérin..., op. cit., $3^{e}$ édition, p. 206.

51. Ibid., p. 207.

52. Ibid., p. 208. 
piémontaises. Le Supérieur du couvent lui fait remarquer une coïncidence prophétique qui plaît à Guérin : «Vous vous appelez Joseph, vous vous êtes battu hier, jour de la fête de saint Joseph de Copertino, vous avez été déposé devant cet autel dédié à saint Joseph; demain, vous serez transporté à Osimo, où mourut le même saint ; peut-être serez-vous mis dans notre église, où l'on conserve le corps de saint Joseph $»^{53}$. Deux jours plus tard, le jeune homme écrit à son curé, à Noirmoutier, se disant prêt à accepter le sort que lui réserverait la divine providence : «Je suis blessé d'une manière grave sinon mortelle; je suis très heureux d'avoir pu me sacrifier pour une si belle cause. Je n'ai fait que mon devoir, mais je l'ai fait consciencieusement. [...] Si le bon Dieu veut m'appeler à lui, consolez mes parents; s'il veut me conserver la vie, qu'il en soit béni $»^{54}$. Son agonie dura un mois. Il meurt le 30 octobre 1860 , en odeur de sainteté. Son corps « avait d'abord été exposé un jour à l'ambulance d'Osimo, puis cinq autres jours dans une petite église de la ville. Il était alors revêtu d'une soutane, conformément à ses dernières volontés $»^{55}$. Il n'a cependant été rapatrié en France que le 5 février 1861 après que son cercueil a été égaré pendant deux mois. Finalement, ses funérailles ont lieu en grande pompe, suivies de son inhumation dans le petit cimetière ecclésiastique de la Barberie. Immédiatement une intense piété populaire se développe autour de lui. C'est à partir de ce moment-là qu'une série de guérisons miraculeuses va se produire, dont la première survient dans le petit village de Gétigné, à une quarantaine de kilomètres au sud-est de Nantes. Elle concerne Marie Félicité Barré, 42 ans, épouse d'Isidore Plessis, et se déroule de façon progressive la semaine suivant l'enterrement de Guérin.

53. Julien S. Allard (abbé), Le Volontaire Joseph-Louis Guérin..., op. cit., $3^{\mathrm{e} e ́ d i t i o n, ~ p . ~} 214$.

54. Ibid., p. 211.

55. Jérôme Biteau, Robert Guilbaud, « La restauration du monument funéraire de Joseph-Louis Guérin », dans L'Avant-Garde, nouvelle série n ${ }^{\circ}$, juillet 2015, p. 17. 


\section{GUÉrisons MIRACULEUSES : UN CLERGÉ PRUDENT MAIS LOIN D'ÊTRE HOSTILE}

Depuis plusieurs jours, Marie Plessis subit le martyre ${ }^{56}$. Cela fait cinq ans que de nombreux maux la font souffrir à intervalle régulier depuis la naissance de son huitième enfant, mais en ce début du mois de février 1861, les douleurs sont de plus en plus persistantes. La malade a beaucoup maigri, des plaies purulentes aux deux jambes sont apparues qui l'obligent à rester alitée ; très affaiblie, en proie à de nombreux malaises, elle ne se lève que très rarement. Les jours passent et les visites régulières du docteur Robinière, médecin à Clisson, n'y changent rien. Une première opération d'un polype s'est avérée inutile et le praticien pense qu'elle est atteinte d'un cancer. Le 2 février, il fait d'ailleurs part à Isidore Plessis de ses craintes et lui souffle de ne pas attendre « de guérison solide et durable » pour son épouse. Elle reçoit le SaintViatique.

À Gétigné comme dans toute la région nantaise, on sait que le corps du jeune Joseph-Louis Guérin, mort pour le pape «en héros et en saint» doit arriver à Nantes pour y être inhumé. L'enterrement a lieu dans deux jours et l'abbé Coquet, qui la visite quotidiennement, fait part à la malade de son souhait de s'y rendre. Le prêtre sent que la fin est proche mais peut-être espère-t-il secrètement «quelque chose » de l'arrivée du corps de celui dont tout le monde, ici, connait la réputation, même si aucune guérison miraculeuse n'a encore été rapportée. Une notice sur Guérin avait été publiée à la fin de l'année 1860 et elle avait été rapidement épuisée ${ }^{57}$ :

«Joseph-Louis Guérin, il est vrai, était inconnu presque de tous. Mais ses lettres qui avaient fait couler les larmes de tous les yeux, avaient rendu son nom populaire et lui avaient conquis tous les cœurs. On s'était attaché à lui comme au plus beau type du soldat défenseur de la foi ; tout le monde l'aimait et l'admirait $»^{58}$.

56. $\mathrm{AD} 44$, fonds $125 \mathrm{~J}-7 \mathrm{G} 2$, Lettre d'Auguste Coquet, vicaire de Gétigné, à l'Évêque de Nantes, s.d., mais vraisemblablement de février 1861, 23 pages manuscrites.

57. Marius Faugeras, «Un aspect local de la question romaine: l'aide nantaise au Saint-Siège (1860-1870) - $2^{\mathrm{e}}$ partie », dans Annales de Bretagne et des pays de l'Ouest. Tome 91, numéro 4, 1984. p. 402.

58. Julien S. Allard (abbé), Le Volontaire Joseph-Louis Guérin..., op. cit., $3^{\mathrm{e} e ́ d i t i o n, ~ p . ~} 286$. 
Il part donc pour Nantes le mardi 5 février $^{59}$. L'un de ses confrères a décrit la ferveur de la foule nombreuse venue assister aux obsèques :

«L'affluence fut si grande que, pour satisfaire la piété des fidèles, on fut obligé de transformer le parloir en chapelle ardente. Le corps du vertueux séminariste, revêtu de la soutane et du rochet romain, les mains jointes, la barrette sur la tête, tel, au reste, qu'il était venu d'Osimo, fut exposé dans sa châsse ; des cierges étaient allumés, l'encens brûlait, ses condisciples à genoux priaient autour de lui. Quatre séminaristes en habit de chœur étaient occupés à faire toucher au mort des objets de piété ; encore ne pouvaient-ils suffire, tant l'empressement de la foule était grand ! C'était à qui emporterait un souvenir. Tout le monde voulait voir, admirer et prier le jeune martyr, rendre ses devoirs au saint, au petit saint, comme on l'appelait. Du moment où l'on ouvrit les portes, une procession de visiteurs s'établit et ne cessa de défiler, pendant les deux jours que le corps fut exposé » ${ }^{60}$.

L'abbé Coquet en rapporte une médaille qu'il avait « fait toucher à la figure et aux mains de Joseph Guérin » ainsi que «quelques cheveux du martyr [qu'il] avait pu saisir à la dérobée pendant que des séminaristes les coupaient devant [lui] ». À son retour, Marie est en vie mais toujours « bien souffrante ». Il lui passe la médaille autour du cou. C'est la première fois qu'un témoignage relate le fait qu'un objet ayant été en contact avec la dépouille du jeune Zouave est utilisé avec l'espoir d'une guérison, même si l'abbé ne précise pas son intention : "Cela lui fit beaucoup de plaisir », écrit-il simplement, sans que l'on puisse déterminer s'il s'agit là d'un véritable soulagement à ses maux ou si le geste de son confesseur l'a particulièrement touchée.

Il lui propose d'offrir à Dieu une partie de ses maux pour l'Église et pour le pape et lui met dans la main les cheveux de Guérin, «sans intention aucune », souligne-t-il, en lui préconisant de souffrir «à l'imitation de ce petit enfant» et en lui suggérant « de demander sa guérison par l'intercession du martyr». Elle refuse : «Non, non, j'aime mieux mourir, je suis disposée maintenant, plus tard je ne le serai peut-être pas autant! Pourtant je sais que je l'obtiendrais si je la demandais ».

59. Que ce soit dans les quelques publications ou les lettres manuscrites évoquant les obsèques de Guérin, la plupart des auteurs ne s'accordent pas sur les dates ou se trompent de jours ; aussi, nous nous référons ici au calendrier de l'année 1861 en prenant pour base la grand messe du 3 février qui correspond bien à un dimanche.

60. Julien S. Allard (abbé), op. cit., p. 286-288. 
Le vendredi suivant l'inhumation de Guérin, le docteur Robinière annonce qu'il n'y a plus aucun espoir d'amélioration de l'état de santé de sa patiente. Son état décline rapidement, ce qui encourage l'abbé Coquet à lui proposer à nouveau de demander sa guérison ; il lui développe même les motifs qui devraient :

«L'engager à faire cette demande à Dieu par l'intercession de Joseph Guérin : 1. La gloire plus grande de Dieu qui en résulterait. 2. L'exaltation de la Sainte Église. 3. La gloire des défenseurs du SaintSiège et l'élan que ce miracle ne manquerait pas de donner pour la défense de cette sainte cause. 4 . Du bien spirituel de sa famille si elle restait encore quelques années sur la terre pour élever ses petits-enfants dans la crainte de Dieu. Peut-être aussi la conversion de son médecin ».

La malade finit par accepter. L'abbé l'aide à formuler quelques paroles en lien avec les trois premiers motifs plus particulièrement. Seuls «ses remèdes » semblent lui faire du bien: «C'étaient le crucifix qu'elle avait constamment à la main, la lecture de la notice sur Joseph Guérin, de l'esprit de saint François de Sales et la pensée de sa délivrance prochaine », auxquels s'ajoutent les cheveux de Guérin, qu'elle garde aussi dans la main, et qu'il fait mettre par précaution dans un petit linge afin qu'elle ne les perde pas lors de ses fréquentes crises. Il termine sa prière en insistant « sur la confiance qu'elle devait mettre dans le petit martyr ». Les jours passent, les maux semblent diminuer les uns après les autres : «Aussitôt que je ressens [des douleurs], j'applique les cheveux à l'endroit et elles disparaissent entièrement », dit la malade, jusqu'à sa complète et inexpliquée guérison. Le médecin de Marie Plessis n'a pas témoigné mais pour l'abbé Coquet, il ne fait aucun doute qu'elle est le fruit de l'intercession du jeune Zouave par le biais combiné de la médaille qu'il avait rapportée de son inhumation, des cheveux qu'elle s'appliquait aux endroits douloureux, mais aussi, explique-t-il, par la récitation commune, chaque soir, «d'un Pater et un Ave Maria, trois fois l'invocation Salus Infirmorum, trois fois Ô Marie conçue sans péché, et suivis de cette prière : Mon Dieu, pour la plus grande gloire de Votre Saint nom, l'Exaltation de Votre Sainte Église et la gloire des défenseurs du Saint-Siège, par l'intercession du jeune Guérin, Votre Martyr, guérissez-la ».

Ce fait miraculeux, relaté par un curé à la demande de son évêque, est donc le premier d'une longue série qui s'étend de 1861 à 1866, puis réapparaît en 1873. L'année 1861 est d'ailleurs 
particulièrement prolixe puisque trente guérisons sont recensées contre six en 1862, une en 1863 , une en 1864 , une en 1865 , une en 1866 et une en 1873. La majorité d'entre elles se sont produites dans le diocèse de Nantes (26), les autres dans le diocèse d'Angers (9), en Vendée (1), à Paris (1) et à Rome (2). Trois autres guérisons ne précisent aucune indication de lieu. Les moyens employés pour obtenir l'intercession du jeune martyr sont une ou plusieurs visites directes au tombeau ( 9 cas), des visites indirectes, une personne s'étant dévouée pour un malade ( 2 cas), la récitation de neuvaines ( 16 cas, dont 4 couplés avec une visite au tombeau). Certains malades utilisent conjointement pèlerinage, neuvaines et applications de reliques (cheveux, fragment de soutane, de ceinture, de linceul ou une médaille ayant touché son corps). À l'exemple de Marie Plessis, «on relève dix-huit exemples où les reliques agissent par contact direct dont un cas particulier à signaler : celui d'un enfant de dix ans guéri par la proximité ignorée des cheveux du Zouave, déposés en des bagages confiés pour quelques heures au père de l'enfant $»^{61}$. À signaler aussi deux guérisons subites après une visite au tombeau, en 1865 et 1873 : celle d'une petite sœur des pauvres impotente, le 18 novembre 1865, et celle d'une femme d'un quartier populaire de l'agglomération nantaise (Chantenay), impotente depuis 11 ans.

Marius Faugeras a dressé la typologie des personnes guéries. En y ajoutant les guérisons inédites de 1865, 1866 et 1873, on note ainsi trente-deux guérisons féminines contre dix masculines, et neuf guérisons d'enfants âgés de 4 à 11 ans. Si la plupart des milieux sociaux restent inconnus, sont concernées trois religieuses, un séminariste, deux cultivatrices, un tailleur d'habits, une domestique, une lavandière, les deux enfants d'un portier d'hôtel, une institutrice publique, et un lieutenant des Zouaves pontificaux. Les pathologies, elles, sont pour l'essentiel des paralysies et hémiplégies (10), des abcès et plaies infectées (5), des cas de cancer (4), des affections pulmonaires (5) ou des affections oculaires et cécité (2), mais plusieurs malades souffrent de divers problèmes de santé à la fois, comme c'est encore le cas avec Marie Plessis.

Les guérisons «miraculeuses» de l'année 1861 n'ont fait que renforcer le prestige de Joseph-Louis Guérin, déjà objet d'une

61. Marius Faugeras, op. cit., p. 133. 
large canonisation populaire, malgré un corps médical partagé et un clergé prudent. Sur la quinzaine de témoignages de praticiens ayant suivi des patients guéris par l'intercession supposée de Guérin, cinq leur reconnaissent, cependant, un caractère « étonnant $»^{62}$, 《extraordinaire $»^{63}$ voire $«$ miraculeux $»^{64}$ de leur état de santé. D'autres, ayant examiné d'autres malades, sont plus prudents: sans réfuter le caractère «inattendu » de leurs guérisons, ils ne souhaitent pas «s'avancer légèrement..., ne pas donner comme extraordinaire ce qui pourrait, plus tard, être expliqué naturellement $»^{65}$. Un seul se veut résolument hostile, encore convient-il de dégager le fond de la forme car il s'agit du Dr Dreux, par ailleurs maire d'Aigrefeuille, qui semble ne pas vouloir rédiger de mot à l'évêché sur la guérison de sa patiente, l'institutrice du village, craignant d'être taxé de «charlatanisme ». Il s'y plie finalement après quatre mois de gesticulations contradictoires. Le clergé, lui aussi, semble particulièrement prudent dans ses conclusions, et à l'emploi du mot «miracle», il lui préfère les termes de «guérison extraordinaire» ou «quelque chose d'inexplicable selon les lois de la nature $»^{66}$. Depuis le traité du pape Benoit XIV, au XVIII ${ }^{\mathrm{e}}$ siècle, qui ne voulait pas que l'on retienne comme faits miraculeux, les guérisons que l'on peut expliquer par l'influence du système nerveux, et qui avait le premier établi ces critères scientifiques stricts pour le discernement de ces phénomènes, l'Église montre, en effet, une certaine désaffection pour les guérisons miraculeuses ${ }^{67}$. Les importantes avancées de la médecine au XIX ${ }^{\mathrm{e}}$ siècle ont ensuite marqué

62. Témoignage d'un médecin de Tiffauges ayant suivi Henriette Braud, de Torfou, malade depuis 22 ans, dont l'état avait été jugé incurable. Cité par Marius Faugeras, op. cit., p. 137.

63. Témoignage du médecin d'Anne Chéneau, du Bignon, couverte de plaies qui ont complètement guéri.

64. Témoignage du médecin d'Anne-Marie Moriceau, de Montbert, qui confesse l'amélioration jusqu'à la guérison complète alors qu'elle ne recevait plus aucun soin depuis deux mois.

65. Témoignage d'un médecin de Boussay ayant examiné Geneviève Bonin, qu'il avait considérée comme incurable.

66. Marius Faugeras, op. cit., p. 139.

67. Cardinal Prospero Lambertini, De servorum Dei beatificatione et beatorum canonizatione, Bononiae, 1734, Livre IV, Partie I, Chap. VIII, $\mathrm{n}^{\circ} 2$. Le Cardinal Lambertini est devenu le pape Benoît XIV en 1740. Voir l'édition italienne du texte (Cité du Vatican, Libreria editrice Vaticana, 2010) et la synthèse de Francesco Ricciardi Celsi, Beatificazione e canonizzazione nella dottrina di Benedetto XIV, Roma, Aracne, 2011. 
«le début d'une longue période de silence pour l'autorité catholique. Désormais le domaine de l'extraordinaire chrétien se retrouve marginalisé dans les discours officiels de l'Église » ${ }^{68}$, même si l'on constate, par ailleurs, une recrudescence des apparitions mariales ${ }^{69}$. Pour certains scientifiques comme pour certains hommes d'Église, la force de l'esprit ou l'effet placebo joueraient un rôle non négligeable dans le pouvoir de guérison. Selon le neurologue Hippolyte Bernheim, chef de l'École de Nancy spécialisé dans la suggestion par l'hypnose, cette «attitude de transformer une idée en acte permettrait d'expliquer scientifiquement les guérisons miraculeuses $»^{70}$. «Il déclare même que les miracles de Lourdes sont d'une nature comparable aux guérisons qui peuvent être obtenues par la pratique de la suggestion: Il suffirait d'intégrer sans aucune critique et doute, l'idée, venant d'une autre personne, que l'on va guérir $»^{71}$. Il ne s'agit pas d'opposer ici la science à l'Église, cela d'autant plus que des scientifiques actuels comme le Dr Édouard Zarifian reconnaissent que «la foi en Dieu, la prière, la méditation apportent une sérénité intérieure, un apaisement qui aident à cultiver les forces de guérir. » Le message des Évangiles donne de l'espoir, et c'est aussi, selon lui, ce que le médecin doit insuffler à son patient ${ }^{72}$, ce qui correspond bien à l'attitude de l'abbé Coquet envers Marie Plessis. L'effet placebo serait responsable, selon le Dr Zarifian, d'au moins $30 \%$ des guérisons dans toutes les pathologies fonctionnelles et organiques. Si les progrès de la science semblent plutôt avoir freiné la reconnaissance de guérisons miraculeuses d'une Église attentive à la question, particulièrement au XIX ${ }^{\mathrm{e}}$ siècle - sur environ 1100 miracles reconnus dans le monde ${ }^{73}$, 164 l'ont

68. Justine Louis, L'Église catholique face à l'extraordinaire chrétien depuis Vatican II, Thèse de doctorat d'Histoire, Université Lyon 3, 2007, p. 25.

69. Joachim Bouflet, Philippe Boutry, Un signe dans le ciel. Les apparitions de la Vierge, Grasset, 1997, $480 \mathrm{p}$.

70. Dr. Hippolyte Bernheim, De la suggestion et de ses applications à la thérapeutique, deuxième édition corrigée et augmentée, Paris, Octave Doin éditeur, $1888,576 \mathrm{p}$.

71. Justine Louis, L'extraordianaire chrétien... op. cit., p. 57.

72. Dr. Édouard Zarifian, La force de guérir, Paris, Odile Jacob, 1999, 190 p. Cité par Justine Louis, op. cit., p. 58.

73. Neuf miracles reconnus sur dix sont des guérisons, dans Pierre Delooz, Les miracles, un défi pour la science? Bruxelles, Duculot, 1997, 259 p. et Patrick Sbalchiero (dir.), Dictionnaire des miracles et de l'extraordinaire chrétiens, « Miracles », Pierre Delooz, p. 542-543. 
été au XIX ${ }^{\mathrm{e}}$ siècle contre 213 au XVIII ${ }^{\mathrm{e}}-$ le $\mathrm{XX}^{\mathrm{e}}$ siècle fait cependant mentir cette théorie puisque 546 cas ont été avalisés, soit près de $50 \%$ de la totalité des guérisons miraculeuses reconnues depuis au moins quatre siècles.

Localement, le clergé reste plutôt enthousiaste; nous l'avons vu avec l'abbé Coquet, il en va de même avec le curé de Torfou qui signe les rapports sur les guérisons de Saint-Macaire «Béziau, curé de Torfou qui $a v u$ ». Le curé de Puymaufrais, en Vendée, revendique l'origine du petit Zouave qui, bien que né en Bretagne, avait passé une partie de son enfance à Noirmoutier ; quant au desservant de La Chapelle-des-Marais, il n'hésite pas à conseiller à son évêque, Mgr Jaquemet, souffrant de «laryngalgie », d'invoquer Guérin pour être guéri! On ignore si le prélat a suivi ce conseil, toutefois, souligne Marius Faugeras, lorsqu'il fut à l'article de la mort le 8 décembre 1864, « il confia à son médecin : "J'aurais pourtant eu besoin de cinq années encore...". Ces cinq années lui furent accordées très exactement puisqu'il mourut dans la nuit du 8 au 9 décembre $1869 \gg^{74}$. Les deux témoignages inédits du grand séminaire, datés des années 1865 et 1866, montrent d'ailleurs que l'évêque se préoccupait de rassembler des rapports précis de ces événements et en avait confié la garde au supérieur du séminaire. La lettre du curé relatant la première guérison à l'évêché se voit, en effet, annotée par le vicaire général Laborde du commentaire suivant : "Monseigneur prie M. le supérieur du grand séminaire de joindre cette lettre aux autres documents du même genre qu'il a entre les mains », et à la suite de la seconde, Mgr Jaquemet avait écrit au supérieur du séminaire en lui demandant de bien vouloir enquêter sur l'événement. Peut-être est-ce anecdotique, mais la tombe de Guérin se trouvait, par ailleurs, dans «La Barberie », propriété du grand-séminaire, limitrophe de la propriété de Talence, résidence de campagne où Mgr Jaquemet se rendait très souvent étant donné sa mauvaise santé.

L'engouement dépasse les seules frontières de la Bretagne et de la Vendée. En Italie, où deux faits miraculeux ont été recensés, le jeune Zouave jouit d'une belle popularité. Le pape lui-même a fait disposer un portrait de Guérin dans l'antichambre de sa chapelle

74. Victor Martin (abbé), Vie de Mgr Jaquemet, Paris, Poussielgue, 1899, p. 499, nº 1, cité par Marius Faugeras, op. cit., p. 139. 
privée de Castel-Gandolfo ${ }^{75}$. Les «miracles italiens » présentent la particularité d'avoir été réalisés à la suite d'apparitions de Guérin, alors inconnu aux deux malades.

Le premier, resté célèbre chez les soldats du pape, est le songe du lieutenant Stanislas Garroni, blessé le même jour que Guérin à Castelfidardo. Un an après, le jeune officier était tombé gravement malade à tel point que, dans la nuit du 13 décembre 1861, les médecins du régiment l'avaient cru perdu et que l'aumônier lui avait administré les derniers sacrements. Le malade se serait endormi, et peu après, Guérin lui serait apparu en songe, lui annonçant que dans quatre jours il serait guéri. À son réveil, il raconte la chose à son frère, l'abbé Garroni, à qui il fait une description précise de celui qui était venu le visiter et qu'il n'avait jamais vu. «Peut-être était-il à l'hôpital militaire avec toi ? lui suggère son frère. - Non, dit-il, le bienheureux m'a dit qu'il était actuellement caporal des Anges du Paradis, que je ne doute pas que je ne mourrai pas ${ }^{76}$. L'abbé, qui avait engagé son frère à invoquer l'intercession du Zouave blessé lors de la même bataille, «lui montra alors le portrait [de Guérin] et l'officier y retrouva celui qui lui avait parlé dans son sommeil $\gg^{77}$.

Le 4 mars 1863, c'est à une jeune fille de 15 ans complètement aveugle, la nièce du curé de Saint-Roch, à Rome, que Guérin serait apparu en uniforme et lui aurait demandé ce qu'elle voulait obtenir de ses prières : «La vue! aurait-elle répondu. C'est bien, lui dit Guérin, continuez de prier le bon Dieu ». Deux jours plus tard, en fin d'après-midi, il lui apparaît de nouveau en Zouave et lui dit: «Nanina, tes prières sont exaucées; lève-toi, tu vois », ce qui se serait, en effet, aussitôt vérifié. La jeune fille descend alors à l'église et c'est en voyant des Zouaves dans les rues qu'elle raconte à son oncle qu'il s'agissait de l'uniforme du jeune homme qui lui était apparu, et qu'elle identifie peu après sur une photographie. La jeune fille a été reçue le 9 mars à Rome par l'abbé Daniel, originaire de Nantes, auquel elle a relaté son histoire. Le SaintSiège, bien au fait de ces deux cas, ne semble pas avoir tergiversé

75. Journal de Mgr Daniel..., op. cit., p. 91.

76. Lettre de l'abbé Ignace Garroni au Supérieur du séminaire de Nantes, 10 janvier 1862.

77. Lettre du lieutenant Tuccimei (ami du lieutenant Garroni) à L'AvantGarde, publiée dans le n 269 du $1^{\text {er }}$ mars 1902. 
quant à leur véracité, ni même sur celle d'autres guérisons inexpliquées survenues en France au cours de l'année 1861. Une réponse de Rome, datée du 2 janvier 1862, au courrier du vicaire général de Nantes qui avait alerté les autorités pontificales, précise, en effet, que : "Sur treize faits dont j'ai lu la relation, il y en a six ou sept qui, étant appuyés par les preuves d'usage, sont évidemment miraculeux. Le promoteur de la Foi, un important personnage appelé parfois l'avocat du diable a dit: le premier point qu'il faut établir à Rome n'est pas celui des miracles mais celui des vertus. De virtutibus et miracolis... C'est un nouveau patron que Dieu veut donner aux militaires dans la personne d'un jeune séminariste qui a, de si grand cœur, donné sa vie pour Son Vicaire $\gg^{78}$.

\section{LA VIE VERTUEUSE D'UN SAINT EN ATTENTE DE RECONNAISSANCE}

La sainteté doit-elle obligatoirement passer par la reconnaissance de faits extraordinaires ? La réponse à la question peut se faire à plusieurs niveaux : "Intercesseur, modèle et témoin, le saint se prête à des lectures polysémiques qui mettent en valeur tel ou tel aspect de la vie de l'Église, de la spiritualité à la pastorale en passant par les pratiques et la dimension évangélisatrice $»^{79}$.

Un saint est avant tout un grand priant. Joseph-Louis Guérin prie avec ferveur, rapporte son camarade Jean-Baptiste Pinsonneau : «Je me souviens entre autres choses qu'ayant été admis tous les deux dans la chambre de Saint Louis de Gonzague au Gèsu à Rome, il pria dans cette sainte chambre avec une telle ferveur que j'en étais moi-même ému en le regardant prier. Il récitait son chapelet tous les jours et quelquefois l'office de la sainte Vierge lorsqu'il en avait le temps. Il communiait aussi très souvent $»^{80}$.

La prière d'un saint est aussi toute de compassion. Il intercède pour les pécheurs et implore la miséricorde de Dieu. Guérin, non seulement prie pour les autres, mais : «S'oubliant lui-même, il

78. Cité par Marius Faugeras, op. cit., p. 140.

79. Benoît Pellistrandi, «La sainteté contemporaine », dans Mélanges de la Casa de Velázquez, 33-2 | 2003, p. 165-184.

80. Lettre de Jean-Baptiste Pinsonneau au Supérieur du séminaire de Nantes, op. cit. 
faisait volontiers [leur] éloge et avouait avoir tort quand il devait avoir raison. [...] Vif et prompt, il était cependant plein de douceur et d'aménité, et dominait son caractère au point de ne pas s'irriter et se fâcher. [...] Son exemple animait les uns et ses paroles encourageaient, consolaient les autres $»^{81}$.

Guérin ne se ménageait jamais ; nous l'avons vu avec l'épisode des heures de marche effectuées pour aller chercher de l'eau pour sa section. Pourtant, aux dires de ses camarades, «jamais sa gaîté ne se démentit, jamais son courage ne parut épuisé », pas même durant son agonie au cours de laquelle il fait preuve d'un comportement exemplaire: "On ne saurait dire la patience avec laquelle Guérin souffrait les douleurs de sa blessure, supportant sans se plaindre la privation des choses nécessaires $»^{82}$, précise le curé de Saint-Marc, un religieux dominicain qui l'a assisté durant ses derniers jours. Domenico Salvatori, un jeune clerc attaché au cardinal-archevêque d'Osimo qui s'était lié d'amitié avec JosephLouis confirme que son agonie a été très pénible, mais : «Mon Dieu! Quel exemple d'une belle mort! Il priait, avec ferveur et baisait le crucifix que je lui présentais, ce qui a diminué ses souffrances. [...] Souvent aussi il avait manifesté le désir de mourir le jour de la fête de tous les Saints, et Dieu a exaucé sa prière ${ }^{83}$.

Sachant que sa dernière heure arrive, le jeune Zouave a écrit une ultime lettre à ses parents; un courrier empreint d'amour, d'espérance et de ferveur chrétienne :

«Mes bien chers parents, Je ne puis pas vous quitter pour toujours sans vous exprimer et vous redire tout mon amour et toute la tristesse que j'éprouve ; mais le bon Dieu le veut ainsi, bénissons-le et adorons-le. Nous nous reverrons un jour au ciel : que cette pensée vous excite et vous encourage à demeurer toujours fervents chrétiens. Je vous en supplie à genoux : que le découragement ne vienne pas vous abattre, et que le désespoir ne s'empare jamais de vous. Le sacrifice est grand, mais que votre courage soit plus grand encore. Recommandez-moi aux prières de tous ceux qui s'informeront de moi. Mais il faut que je vous dise que je vais avoir ici une trentaine de messes, probablement davantage, et encore ailleurs. Je ne veux pas vous imposer de trop grands sacrifices $»^{84}$.

81. Lettre d'Auguste Padioleau au Supérieur du séminaire de Nantes, op. cit.

82. Julien S. Allard (abbé), op. cit., p. 222-223.

83. Lettre de Domenico Salvatori au Supérieur du séminaire de Nantes, 31 octobre 1860, citée dans Julien S. Allard (abbé), op. cit., p. 271.

84. Lettre de Joseph Guérin à ses parents, citée dans Julien S. Allard (abbé), op. cit., p. 272-274. 
À une vie vertueuse, on peut donc ici ajouter une mort héroïque. Toutefois si cette vie de sainteté est essentielle pour être reconnu comme un saint de l'Église, le surnaturel extraordinaire peut contribuer à l'attester. Dans le cas de Guérin, malgré le recensement de tant de guérisons dites miraculeuses, aucun procès n'a été ouvert. À l'inverse, malgré une certaine prudence naturelle de l'épiscopat, aucune opposition sérieuse ne s'est manifestée. Encore cette prudence est-elle à relativiser puisque de hautes personnalités ecclésiastiques, à commencer par le pape lui-même, n'étaient pas contre l'idée de donner un saint à ses défenseurs en la personne de Guérin. Le Saint-Père aurait même «invité Mgr Jaquemet, à commencer le procès de canonisation ${ }^{85}$. L'évêque de Nantes, était, pour sa part, loin d'être hostile à l'idée que le petit Zouave pût être un instrument de Dieu dans la défense de la papauté, même s'il pensait qu'il «appartenait à la cour de Rome de se charger de la procédure et des frais considérables qu'elle entraînait $»^{86}$, Guérin étant mort dans les États pontificaux. Au mois de janvier 1862, après la grande vague d'une trentaine guérisons inexpliquées recensées l'année précédente, l'évêque de Nantes répondit à son collègue de Blois qui l'avait interrogé sur le jeune thaumaturge :

«Beaucoup de grâces, de guérisons, surprenantes ont déjà été obtenues par son intercession, je ne dis pas de guérisons miraculeuses... D'ailleurs, aucune enquête canonique n'a encore été faite et je n'ai jusqu'ici sous les yeux que des récits spontanés de témoins oculaires, confirmés par l'acclamation de populations entières. Ces récits dans leur naïveté et leur simplicité sont propres à nous apporter de la consolation au milieu de nos tristesses... je le répète, Mgr, je ne prétends pas décider encore s'il y a ici dérogation certaine aux lois de la nature. Mais j'admire en silence dans un si grand nombre de faits, la coïncidence merveilleuse de la prière et du simple contact d'une relique du petit zouave avec la guérison instantanée ou se produisant à la fin d'une neuvaine... Ne vaudrait-il pas encourager, récompenser le dévouement de cette poignée de braves jeunes gens qui sont encore debout pour la défense du Saint-Siège et montrer à tous que cette cause est la sienne ?.... $»^{87}$.

Trois mois plus tard, le 4 avril 1862, une commission composée du vicaire général Charles Laborde et de Constant Guitter,

85. L'Avant-Garde, $\mathrm{n}^{\circ}$ 268, 15 février 1902.

86. Ibid.

87. Lettre de Mgr Jaquemet, citée par Marcel Launay, Le diocèse de Nantes..., op. cit., tome II, p. 740. 
professeur au Grand Séminaire, a officiellement enquêté sur les guérisons de Bignon et d'Aigrefeuille. Par ailleurs, le vicaire général François-Marie-Benjamin Richard de La Vergne, le même qui, en 1886, est devenu archevêque de Paris avant d'être nommé cardinal en 1889 , et avait commencé le procès pour la béatification du curé d'Ars lorsqu'il était évêque de Belley en 1871, s'est mis en relation avec Rome dès la fin de l'année 1861. Proche des Zouaves, il leur a d'ailleurs rendu visite en 1863 en compagnie de l'abbé Daniel. Pourtant, aucun début d'instruction ne voit le jour. Guérin est un saint pour l'immense foule de fidèles qui se presse, chaque dimanche sur sa tombe, des années durant, mais pas pour l'Église.

Un fait, cependant, pourrait apparaître comme une raison de ne pas pousser plus en avant la procédure de béatification de Guérin : non seulement sa mère a conçu son aîné hors mariage mais, de plus, les deux parents étaient mineurs. Une lettre, écrite par le recteur de Sainte-Pazanne au vicaire général Richard, explique que le séminariste a grandi «sicut lilum inter spinas », et relate, «avec une certaine répugnance, $[\ldots]$ un assemblage de tristes circonstances : je veux parler surtout de l'honorabilité de la famille du pieux et saint martyr et du degré d'estime dont elle pouvait être environnée. Du côté paternel, rien touchant les ascendants ou collatéraux à citer de consolant. Presque tous à laisser dans l'ombre. Quant au père et à la mère, une triste vérité qui n'est ignorée et malheureusement oubliée de personne, c'est que leur conduite avait été hélas bien scandaleuse, leur premier enfant est né une vingtaine de jours avant la célébration de leur mariage. On connaît du reste l'extrême légèreté de caractère de la mère. [...] Sans parler des dettes dans la maison par suite d'une mauvaise administration $»^{88}$.

Pierre-Auguste Guérin, premier enfant et fils naturel de Pierre Guérin et Anne Beillevaire, est, en effet, né le 15 octobre 1835 et ses parents se sont mariés le 3 novembre de la même année. La « faute », pas forcément isolée dans la région, a été réparée et le sacrement a bien été donné aux époux quelques jours après la naissance du bébé. Ce n'est sans doute pas dans l'esprit de l'évêque 1865.

88. Lettre du recteur de Sainte-Pazanne au vicaire général Richard, 17 février 
ni de son vicaire général de reporter sur Guérin les fautes de ses parents, mais peut-être était-il prudent de ne pas provoquer les ragots, médisances et ricanements dans un village où la sainteté de Guérin semble difficile à envisager par une population d' « esprits irréligieux et moqueurs qui déversent le mépris qu'ils ont du jeune homme sur ses parents et alliés. Allons saint Guérin $!{ }^{89}$. Le recteur de Sainte-Pazanne se dit «attristé $»^{90}$, mais prend soin d'étayer ses dires en joignant, au dossier, l'acte de naissance de Pierre-Auguste Guérin et celui du mariage de ses parents.

Le contexte politique national voire international peut également expliquer cette prudence. Il est, en effet, difficile pour un évêque, Monseigneur Jaquemet, haut fonctionnaire sous régime concordataire, de faire instruire le procès en béatification d'un «martyr de Castelfidardo» quand l'agression italienne et les annexions qui ont suivi se sont produites avec l'assentiment de Napoléon III dont les troupes restent, jusqu'en 1870, le meilleur garant de l'indépendance de Rome. La fin des États pontificaux le 20 septembre 1870 après la prise de Rome par les Italiens, le licenciement du Régiment des Zouaves dans la foulée et la guerre de 1870 qui vient de renverser l'Empire, ont sans doute, plus que les considérations d'ordre privé, détourné l'attention de l'Église d'une cause qui ne semblait plus avoir lieu d'être, risquant même de devenir embarrassante dans une France républicaine et de plus en plus laïque, quand les anciens Zouaves les plus en vue affichaient leur monarchisme avec ostentation. Les Zouaves pontificaux ont été la «mauvaise conscience» du gouvernement français qui, en 1860, avait été peu enclin à la présence de compatriotes au sein d'un corps de volontaires pontificaux destiné à s'opposer aux Italiens, ils sont devenus depuis la fin de guerre des anciens combattants encombrants. La béatification de l'un des leurs est alors délicate.

En 1926, à Nantes, un dossier rassemblant une importante correspondance, des témoignages de contemporains et même des reliques du jeune homme a, cependant, été constitué. Par qui ? L'énigmatique signature «J. R. » au bas du rapport peut laisser penser qu'il s'agit de l'abbé Jean (Baptiste) Russon, archéologue et

89. Ibid.

90. Ibid. 
historien qui a, par ailleurs, suivi ou monté des dossiers du même ordre. Ceci n'est qu'une hypothèse, le fonds Russon, conservé par ailleurs ne mentionne pas ce dossier et ni Les Semaines Religieuses du diocèse de 1925-1926 ni les courriers de l'évêque Mgr Le Fer de La Motte ne l'évoquent. Dans quelle intention ? Cela n'est pas précisé non plus : les motivations d'un tel travail n'apparaissent nulle part, ni sa destination, pas plus que les noms des personnes impliquées ou de l'office qui soutenait l'opération. Ce dossier suivit-il jusqu'à Rome ? Aucune trace ne l'atteste et aucun procès relatif à Guérin n'est recensé aux Archives Secrètes du Vatican ${ }^{91}$. Sans doute s'agit-il d'un reclassement du dossier des années 1860, « avec de facto, la volonté de constituer - a minima - un fonds d'archives pour parer à toute éventualité ${ }^{92}$.

Le procès en béatification de Joseph-Louis Guérin n'aura donc jamais été ouvert; seule la réalisation d'un dossier, toujours disponible, aura été amorcée. Le petit Zouave, inhumé il y a plus d'un siècle et demi, n'a pas pour autant sombré complètement dans l'oubli : son monument funéraire, qui tombait en décrépitude depuis 1973, a été entièrement restauré en 2014 par le diocèse, et surtout, plusieurs sources indiquent que son nom a été invoqué jusque dans les années 1950 ${ }^{93}$. Joseph-Louis Guérin a, en son temps, été prié par toute une population de fidèles pour lesquels « un cœur qui s'est donné si généreusement à Dieu, qui lui a fait si hérö̈quement le sacrifice de sa vie, ne peut manquer d'être toutpuissant dans le ciel $»^{94}$; peut-être aussi a-t-il conforté certaines vocations sacerdotales, comme celle de son ami Pinsonneau qui est devenu curé d'Arthon-en-Retz ${ }^{95}$ (Loire-Atlantique). Bien que ce dernier ait eu conscience de ses petits défauts, il n'a jamais douté de la sainteté de son condisciple.

Finalement, le cas Guérin n'aura officiellement divisé ni la communauté médicale ni le clergé qui, pour s'être penchés tous deux « jusqu'à un certain point » sur la question, n'ont rien trouvé

91. Archives Secrètes du Vatican, Congregazione dei Riti, Processus, indice 1147.

92. Échanges de mails avec Jean Bouteiller, Archiviste diocésain, 2, 6 et 7 juin 2016.

93. Cité par Marius Faugeras.

94. Julien S. Allard (abbé), op. cit., p. 301.

95. Louis Hubineau (abbé), Monseigneur J.-B. Pinsonneau, Zouave Pontifical, Curé d'Arthon-en-Retz, Nantes, Bourgeois, s.d., 32 p. 
à redire. Il avait toutefois de moins en moins de chance d'aboutir dans la mesure où les papes ont, peu à peu, dû faire le deuil de leurs États; en effet, malgré les protestations de Léon XIII jusqu'en 1890, et les efforts de la Congrégation des Affaires ecclésiastiques extraordinaires pour tenter de récupérer le territoire pontifical confisqué, les relations avec le gouvernement italien finirent par se régulariser pour parvenir, 60 ans plus tard, aux accords du Latran. Avec le temps, le procès de Guérin aurait alors été perçu comme la marque d'une nostalgie profonde, d'un véritable irrédentisme. Le contexte seul, donc, semble avoir joué en sa défaveur car les témoignages, nombreux, vont plutôt tous dans le sens de la volonté populaire des années 1860 , à l'image de celui de l'un de ses anciens compagnons d'armes, le lieutenant Benoist, devenu Procurateur de la Trappe, qui écrit, un mois après la mort de Guérin : "Aucun ne l'aura aimé et compris comme moi pendant les quelques jours où il m'a été donné de pressentir un saint sous l'uniforme de simple soldat $» .{ }^{96}$ C'est sans doute justement ce pressentiment qui n'a cessé de poser question et n'aura pas permis, malgré l'enthousiasme qu'il a soulevé dans l'opinion publique comme au plus haut niveau de l'Église militante, de faire passer Joseph Guérin de la sainteté populaire à celle de l'Église triomphante.

L'histoire de ce jeune catholique français, ultramontain et royaliste, s'inscrit dans un mouvement bien plus large qu'une simple étude de cas. Tant par les circonstances que par les motivations de son action, il est exemplaire de tous ceux qui, animés d'une mystique sacrificielle, ont associé la défense de la Papauté à celle de la Patrie. Le 2 décembre 1870 à Loigny, lors de la guerre contre la Prusse, les anciens Zouaves pontificaux, devenus Volontaires de l'Ouest, ont déployé pour la première fois sur un champ de bataille - et au sein de l'armée française - la bannière du Sacré-Cœur. Une fois de retour à la vie civile, de nouveaux combats les ont portés, ainsi que leurs descendants. Et c'est en zélateurs de cette dévotion au Cœur Sacré ${ }^{97}$ de Jésus-Christ qu'ils ont poursuivi leurs engagements à travers la consécration du régiment, la création de

96. Lettre d'Édouard Benoist, Toulouse, 27 novembre 1860.

97. Daniele Menozzi, Sacro Cuore. Un culto tra devozione interiore e restaurazione cristiana della società, Roma, Viella, 2001, 320 p. 
pieuses associations, l'érection de la basilique de Montmartre et le Vœu national, dont ils figurent parmi les principaux instigateurs, jusqu'à la guerre de 1914-1918, où de nombreux officiers et soldats « cordiphores $»^{98}$ ont suivi la voie ouverte un demi-siècle plus tôt par Joseph-Louis Guérin et plus de 3000 de ses compatriotes.

lgruaz@club-internet.fr

98. Jacques Marx, Le Péché de la France. Surnaturel et politique au XIX siècle, Bruxelles, Espace de libertés, coll. «Laïcité », 2005, 441 p. 


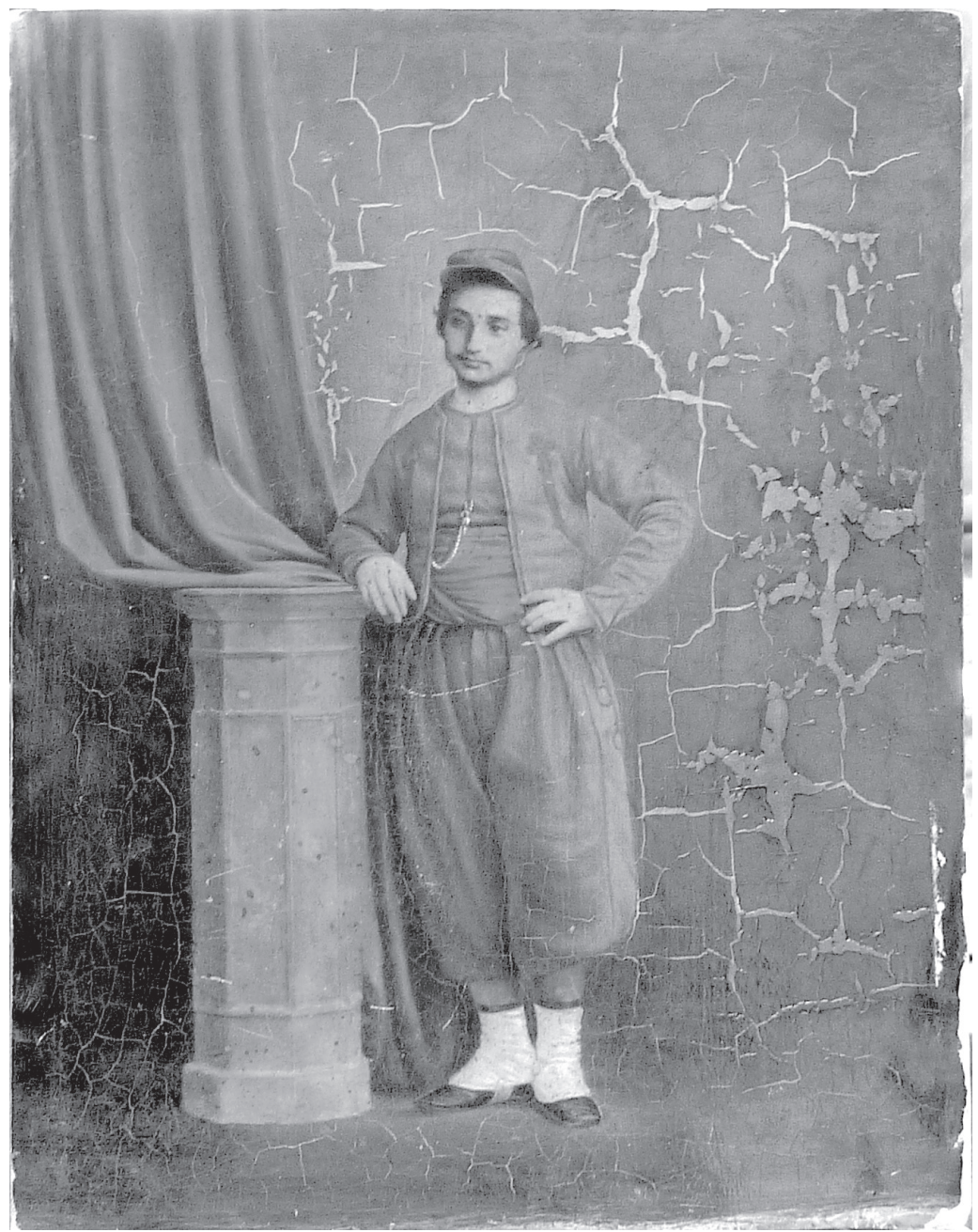

Fig. 1. Portrait du petit zouave Joseph Guérin, tableau sans date ni signature [circa 1860].

(C) Archives historiques du diocèse de Nantes (4F10-17). 


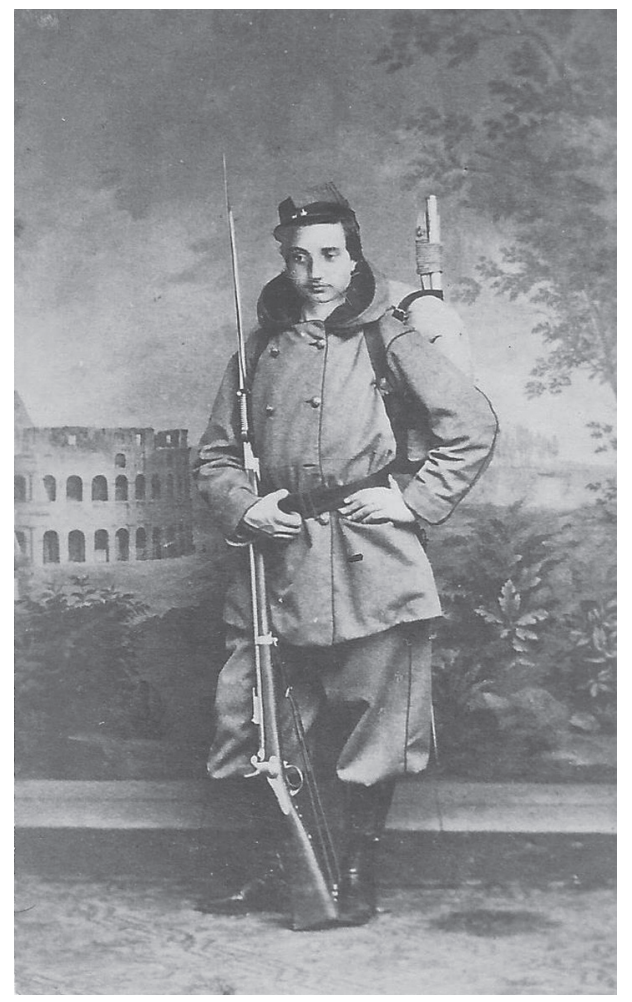

Fig. 2. Joseph Guérin, du corps des tirailleurs franco-belges, en uniforme complet avec paquetage et fusil Minié devant un décor du Colisée. Nantes, 1860. (C) Lieven Gorissen.

Fig. 3. Gisant du soldat Guérin, blessé lors de la bataille de Castelfidardo. Ateliers Saint Joseph, Angers, 1863.

(C) Dominique Ropars.

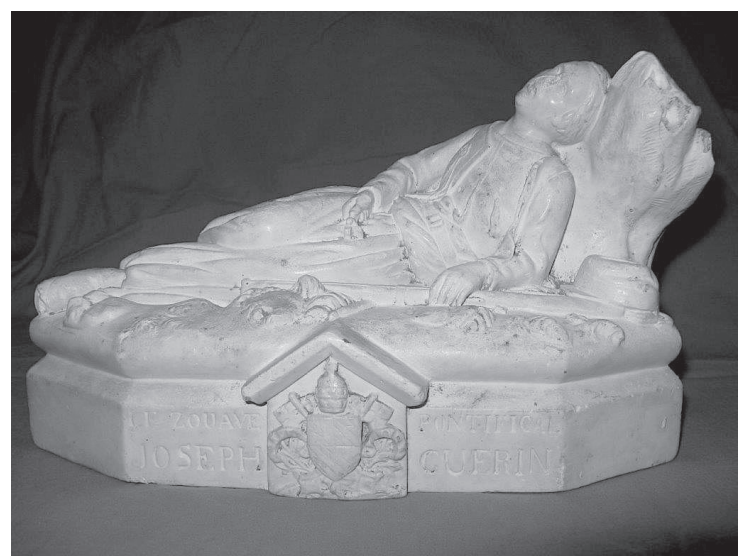

